\title{
BALANCE DEL AÑO Y REFLEXIONES FINALES DESDE WALLMAPU
}

\section{Pablo Mariman Quemenado ${ }^{281}$}

Los sucesos del año 2019 fueron muy ricos en hechos de todo tipo y significaciones. Luego de la muerte de Camilo Catrillanca, en noviembre de 2018, aumentó más la congoja compartida por los pueblos de Chile y el Wallmapu, alimentada además por otras muertes en extrañas circunstancias de dirigentes/líderes que resistían al capital ${ }^{282}$. Creo que, por primera vez, se tocaron cacerolas en el país en repudio al crimen de un mapuche víctima del terrorismo de Estado. Desde entonces, el eje de la discusión en ciertos medios de comunicación de señal nacional hizo sintonía con redes, agrupaciones, territorios, etc., que venían pensando en clave autonomista los escenarios u horizontes que podían situar un desenlace distinto al que el Gobierno actual y los anteriores trataban, empecinadamente, de llevar a la temática indígena.

Ese año también se secó el koliwe (rüngü) aviso de sucesos funestos, tanto en lo natural como

282 Entre muchos, solo menciono, esta vez, el crimen de Macarena Valdés, que se hizo pasar, en un primer momento, como un suicidio en el contexto de la resistencia de su comunidad (en Panguipulli) en contra de las centrales de paso sobre su territorio sin su debida consulta. Sumo a este caso emblemático el de junio de 2020 de Alejandro Treuquil de la comunidad Wente Winkul, de la comuna de Collipulli, quien había denunciado como werken el hostigamiento de Carabineros a su comunidad y había recibido amenazas de muerte por parte de esta misma fuerza pública. 
en lo social, y hubo eclipses de sol. Muchas novedades auguraban los Küymin de las/os MACHI $^{283}$. El Estallido Social fue también comprendido desde esas coordenadas, pues, por lo visto, no estaba programado a manera de una acción política de alguna vanguardia, como lo quería hace ver el Gobierno tras la expresión "estamos en una guerra." Simplemente fluyó a través de todo el país al mismo tiempo que, en el cosmos en que nos situamos y pertenecemos, se daban y se siguen dando otros fenómenos como el COVID-19.

\section{¿Qué hacer o deshacer?}

Antes del 18 de octubre, en las redes en que yo mismo participo había cierta incertidumbre sobre qué se podía hacer para pasar a una fase distinta y con ventajas. El movimiento indígena continental y los mapuche parecían estar en un reflujo. Mientras, quienes gobernaban con soberbia, comprobaban la paradoja colonial de que una cosa es administrar el problema y otra, resolverlo. El Estallido Social de 2019 en Chile sacudió al mismo Wallmapu (país mapuche), creando condiciones políticas - al abrir un proceso constituyente-y orgánicas —al potenciar a los movimientos desde la acción - que no estaban presentes dialogando y que duró hasta cuando la pandemia, como campana de ring, contuvo y paralizó el proceso.

Durante décadas se veía un ensañamiento contra los pueblos indígenas que luchaban. Muchas políticas y prácticas institucionales se habían racializado. Existía una justicia para los chilenos y otra diferente para los mapuche. Carabineros recibía "bonos étnicos" al ser destinados a los focos de conflicto en regiones como La Araucanía. Había una forma de actuar política y policialmente con el nacional (incluyendo al lumpen y al narcotraficante) y otra con los mapuche ${ }^{284}$. Planteé y escribí, en más de una oportunidad, que en los territorios de asentamiento histórico mapuche había cierta confabulación nacionalista entre las clases populares chilenas y las dirigenciales, las que, si bien se peleaban entre ellas, lo que las unía era su negación del "indio", o sea, de un otro no reconocido ni legítimamente valido, más cuando reivindicaba sus derechos políticos territoriales. Los más extremos negaban toda historicidad y agenciamiento indígena en la conquista de sus demandas y derechos, cuestionando hasta la discriminación positiva que las políticas indigenistas implementaban al crear fondos exclusivos para su desarrollo.

283 José Quidel, lonko de los territorios de Itinento y académico, se refiere a este y otros fenómenos transcurridos, o en proceso, que tienen su lectura no solo desde la ontología mapuche, sino también por otros pueblos de Abya Yala. Esos otros acontecimientos también explican los fenómenos que se suceden (entre esos, la misma pandemia) y son poderosas señas que advierten y debieran condicionar ciertos comportamientos a las sociedades y los sistemas que los gobiernan. Ver: Fey ga akuy ti ahtu entonces el día llegó, una lectura de la pandemia desde un mapuche rakizuam En: https://www.comunidadhistoriamapuche.cl

284 En agosto-septiembre 2020, el gremio de camioneros, ante la muerte de uno de sus colegas por un atentado, así como por el caso de una niña herida en una balacera, se propuso como medida de presión cortar la cadena de suministros obstaculizando el tránsito en la carretera 5 sur. Vimos cómo Carabineros dispuso gran cantidad de personal para ayudar en su aparcamiento en las bermas y la presión sobre aquellos que no querían sumarse. El Ministro del Interior se hizo uno con esta causa relacionada a la seguridad y violencia, sin embargo, subterfugiamente el gremio presionaba contra la posibilidad de dejar sin efecto las garantías tributarias de las que gozan (y que no se justifican) así como buscaba acelerar la tramitación de leyes represivas de la protesta social. Hace pocas semanas se anunció, por parte de comunidades de Malleko, la recuperación de predios cuyos procesos son históricos y no han tenido respuesta ni celeridad a través del fondo de tierras de CONADI. El ministro, al respecto, invocó procesos en su contra por buscar romper o poner en peligro la seguridad interior del Estado, sin siquiera haberse efectuado nada. De los posteriores sucesos de Kurakautin, los únicos en proceso son quienes sostuvieron la ocupación municipal y nadie de quienes los fueron a sacar —en pleno toque de queda y coludidos con Carabineros- destruyendo, de paso, las instalaciones. 
Desde ese enfoque, las ideas de alianzas interétnicas eran imposibles salvo con los amigos/as, compañeros/as que, como los estudiantes, siempre están, pero con los trabajadores u otros grupos de la sociedad nacional no se veían posibilidades. Así, llegó el 18 de octubre, la gente desbordó las calles y plazas, se quemaron íconos del modelo neoliberal y una de las cosas sorprendentes es que todos estaban con la wenufoye, entonces, dicotómicamente razonando, ¿no se suponía que estos eran nuestros enemigos? La otredad WINKA, ahora en sus acciones y cuestionamientos al modelo, lo hacen empuñando un emblema. Las banderas son símbolos y tienen lecturas no necesariamente uniformes ni estáticas. Quizás dicen más que un manifiesto o un escrito con tal cantidad de caracteres. Por último, dejan pensando.

Al cumplirse un año del "despertar", "la primavera" o "el Estallido" que sigue removiendo las estructuras del país — también mentales-, es que constatamos lo dinámico del evento y las contradicciones que nos plantea, pues no se trata de posiciones y pensamientos fijos en el tiempo, sino de cuestiones que se están (de)construyendo. Así como entre los mapuche habitan traumas trans generacionales (Vargas, 2017), hay entre los chilenos patologías que reproducen hábitos coloniales que, al encarnarse en sujetos con poder — como jueces, parlamentarios, ministros, empresarios, etc.-, reproducen el racismo (Mariman, 2018). Sin embargo, así como el colonialismo es una de las parteras de estos fenómenos, también está presente o internalizado en la forma de relacionarnos y vivir la realidad (Nahuelpan, 2013). Por eso es significativo ver cómo las deconstrucciones de realidad y/o órdenes son también procesos de descolonización. Estos habrían estado ocurriendo constantemente y en distintos tiempos - más tempranos en unos, tardíos en otros-, dejando huellas que podemos leer desde nuestro presente ${ }^{285}$.

\section{Racismo y terrorismo de Estado}

La dinámica que adquirieron las relaciones interétnicas en el país, en el caso mapuche chileno, no fueron determinadas el año del Estallido, sino unas décadas atrás. La transición de regímenes no tocó el modelo económico instaurado por la dictadura cívico-militar, sin embargo, hubo de cambiar la mirada hacia los pueblos indígenas. Así es como, en los parámetros de las llamadas etnofagias, el modelo neoliberal asume la diversidad cultural en cuanto le es rentable política y comercialmente ${ }^{286}$. Las sociedades, sus necesidades reales y derechos pueden esperar (un reconocimiento que nunca llegó), ser contenidas (interfiriendo derechos por dictámenes del tribunal constitucional) o bien prescindir de las garantías que gozan como las consultas previas, libres e informadas. Si los pueblos, a través de sus comunidades locales, resisten y se oponen, entonces se gatillan sobre ellos los dispositivos

285 Violeta Parra - y, por su intermedio, la música, el arte y la cultura - ya había denunciado la acción de los chilenos contra los mapuche, a diferencia de los cuentistas o novelistas de generaciones literarias de la primera mitad del siglo XX, que describieron las condiciones de desigualdad y racismo en los campos de la frontera, esta vez ella lo hacía en pleno ascenso del protagonismo popular y de la izquierda que pugnaban por cambios radicales en las estructuras económicas y de poder. Sin embargo, el quejido del indio no se escuchaba. Con toda seguridad, la autora captó desde sus honduras las visiones críticas y disconformes que salían desde los cotidianos reduccionales que visitó. Ver: Violeta Parra en Wallmapu (Ramay et AL.2017))

286 Una mirada al fenómeno a escala continental nos la da Díaz-Polanco, 2005. 
legales y policiales ${ }^{287}$. Este racismo institucionalizado en su fase más violenta se expresa en el terrorismo de Estado. El Estado, en su fase expansionista de mediados del siglo XIX, tomó las tierras de pueblos originarios mediante una guerra irregular, en la cual se enfrentó a una sociedad política que contaba con mecanismos de contención y resolución de las tensiones de la convivencia interétnica, como lo hacían a través de los parlamentos.

El racismo se puede travestir de buenas intenciones, reconocer parte del problema aunque negando el resto, obnubilando la relación y la posición del racializado. Entonces, el tema indígena puede volverse un tema de estudio y hasta crearse una comisión o un instituto especializado sobre los mismos, sin embargo, no cambia mayormente nada. Parece conformarse más con los activos culturales posibles de desprenderlos y hacerlos circular, a manera de extractivismo epistemológico, que hacerse cargo de los cuerpos, es decir, de las sociedades y sus instituciones ${ }^{288}$. Al racismo habría que identificarlo o reconocerlo como una conducta que refundó las relaciones interétnicas desde la incorporación forzada del Wallmapu a Chile. Los actos que se han cometido y siguen cometiéndose deben ser abordados como un problema social que afecta y daña la convivencia $^{289}$. Las esperanzas en que de una Convención Constituyente se redacte una Constitución que declare la plurinacionalidad, debieran ir en esa vía, pues se le debe poner freno y sancionar bajo penas los actos naturalizados e "involuntarios" de racismo a que se nos acostumbra, como aquellos declarados de grupos como el APRA o de individuos que publican con una impunidad vergonzosa en redes sociales.

Una de las antesalas del Estallido fue la reacción de la sociedad contra un terrorismo de Estado impune. La encontramos en la muerte de Camilo Catrillanca, la que se supo y difundió antes que los medios monopólicos de comunicación y los agentes de Gobierno hicieran la tarea de desinformar o confundir. Las pruebas que se fueron conociendo con los días y semanas hicieron ver la complicidad en los encubrimientos que hacía el alto mando de Carabineros y el Gobierno. Hasta que, transformado en una crisis política - y como efecto dominó-, empezaron a caer de sus cargos los responsables, evidenciando el poder que han acumulado sobre la vida y la muerte de las personas. Esto, en términos mediáticos, "corrió el cerco" hacia los escenarios políticos

287 Es lo que sucedió bajo el Gobierno de Lagos cuando aplica la Ley Antiterrorista contras comunidades emblemáticas de Malleko. En adelante, y por casi 10 años, la aplicabilidad de ésta se hizo exclusivamente a la causa política mapuche. Ver: Yáñez y Aylwin, 2007.

288 En 2019 otros hechos que no tienen la épica de un conflicto por territorio, nos demuestran este fenómeno. Es el caso de las hortaliceras (TUKUKAFE) que venden en el centro de Temuko desde que este fuerte militar y luego ciudad, se fundó. A ellas, productoras orgánicas en los esquemas de la soberanía alimentaria, se las ha corrido sin miramiento y de la forma más brutal y burda. Las justificaciones del municipio se refieren al orden y al ornato, y se escudan en que propician interculturalidad en otros servicios. No se refiere el gobierno local, a los derechos que les asisten como mujeres indígenas de acuerdo al convenio y otros reglamentos, que es lo que ellas contra argumentan y, por lo cual, insisten en ocupar los espacios en que las hemos conocido desde siempre.

289 El caso del aprisionamiento del lonko Alberto Curamil obedeció a la estrategia de criminalización que el Gobierno yla policía llevan a cabo por medio de seguimientos y montajes. En su caso, los antecedentes más inmediatos fueron su liderazgo y gestión en denunciar la intervención del río Cautín por parte de proyectos hidroeléctricos inconsultos que tendrían grave impacto sobre el medio y sus espacios de significación cultural correspondientes a territorios de comunidades. El caso fallado a su favor en los tribunales permitió finiquitar el proyecto. Al poco tiempo, se le involucra con hechos delictivos de gravedad y se le detiene iniciando un proceso que, sin llegar a una condena, lo mantuvo encarcelado por más de un año. En ese contexto recibe el "nobel verde", Premio Goldman, un reconocimiento internacional otorgado a quienes destacan por su lucha a favor del medio ambiente, el cual fue recibido por su hija en el extranjero. Esto generó una nueva ola de condenas hacia el Estado de Chile, que llevó a cerrar un caso que no tenía pruebas, exculpándolo de las acusaciones y liberándolo. 
Capitulo 10. Página 192

posibles y, como nunca, la palabra "autonomía" era mencionada como un horizonte de convivencia y de superación del estado de cosas. Este hecho y la reacción de la población nacional que se conmovió y protestó, desde el primer momento, por la brutalidad e indolencia del mismo, terminó de echar por abajo el Plan Araucanía, cuya propaganda de los primeros meses ponían en este tipo de prácticas asistencialistas la supuesta resolución de los conflictos de la región y de los mapuche, en particular.

\section{Políticas y estrategias en juego}

El Plan Araucanía se acompañó de una propaganda que hacía ver la solución de los problemas de la Región de La Araucanía con cierta liviandad y voluntarismo, pero no había ninguna novedad en los viejos enfoques productivistas, subsidiarios y asistencialistas que, por lo demás, no asumían en nada la dimensión de los derechos sociales, económicos y culturales; menos los de tipo territoriales y políticos. La derecha, presente en la oposición al segundo gobierno de Bachelet, había hecho de la retroexcavadora de Quintana su campo de enunciación para contrarrestar los aires reformistas que habían dado algo de mística al discurso de la expresidenta. Sin embargo, fue el segundo gobierno de Piñera quien no se hizo problemas en anunciar la discontinuidad y el desmantelamiento de conquistas efectivas en materia de derechos indígenas, como lo fue no volver a ratificar el Convenio 169 luego de sus primeros diez años de vigencia y dejar, asimismo, sin vigencia la Ley de Espacios Marítimos de Pueblo Originarios o Ley Lafkenche. En su diagnóstico, ambos perjudicaban las inversiones y afectaban a las poblaciones.

Ya en pleno 2019 y con la popularidad cayendo en picada, arremeten contra la "tercera pata" de lo que veían como un problema para los indígenas al no disponer de sus tierras como un bien posible de transar, como otros, en el mercado. Sin informar ni acordar con los pueblos indígenas, llaman a una consulta para discutir la intención de destrabar las limitaciones existentes sobre las tierras indígenas que las imposibilitan de ser vendidas a personas no indígenas, o arrendadas bajo ciertas condiciones. Esto causó un movimiento espontáneo de proporciones que le provocó un revés a la ofensiva del ejecutivo. Los distintos pueblos del país compartían una lectura sobre las intenciones profundas del gobierno, asociadas a la expansión del capital frutícola, minero e inmobiliario (Mapuexpress, 2019). Los campos de enunciación a los que nos quiso habituar comunicacionalmente el Gobierno y los gremios, por su intermedio, —antes y durante el 2019- hasta ahora subsumen el conflicto "nacionalitario" que encierra lo mapuche en coordenadas lingüísticas decodificables en dos vías: por un lado, la del terrorismo - que venimos escuchando desde el Gobierno de Lagos y que ha sumado un sufijo al mismo, como el de "narco-terrorismo"- que centra su atención en una violencia que estaría atentando contra la existencia cotidiana de la población de La Araucanía. Y, por otro lado, la propuesta de los gremios (agricultores, camioneros, forestales) con su eslogan "Paz en La Araucanía", para lo cual se exige que el Estado, por una parte, garantice la misma haciendo los esfuerzos por redoblar el control policial y, por otra, repare económicamente a las víctimas. Tanto en el discurso del Gobierno como en el de los gremios, se aprecia una lectura sobre la sociedad mapuche poblada por intereses contrapuestos que la divide en (indios) malos que 


\section{Capitulo 10. Página 193}

ejercen violencia y aquellos (indios) buenos que, como los gremios, particulares y latifundistas, quieren vivir en paz y orden. Desde que se inicia el Estallido y se gesta un camino constituyente institucionalizado, las coordenadas del discurso vuelven a obnubilar la especificidad del tema indígena para instalarlo en la contingencia política nacional. Así, los mismos violentistas ahora son vistos como rojos o zurdos ${ }^{290}$.

\section{Las contra-estrategias en el movimiento mapuche}

Quienes desde el movimiento mapuche abogan por cambios estructurales, invocando para ello los cuerpos de derechos que les corresponden -en particular aquellos relacionados al autogobierno y de naturaleza económica, social y cultural-, no han tenido ninguna sintonía con las iniciativas oficiales que, por ejemplo, impulsa el Plan Araucanía y la militarización del territorio. Luego de la muerte de Camilo Catrillanca, este segmento del movimiento convocó a comunidades de distintos territorios en conflicto a liderar un proceso de reconstrucción territorial y política, ejerciendo sus derechos de autodeterminación en la conformación de un autogobierno. El año 2019 continuaron esta iniciativa que, si bien perfila a un sujeto de derecho como sujeto autonómico, no cuaja del todo en lo práctico. La llegada del Estallido Social y la puesta en marcha de un momento constituyente no ha significado para este grupo una posibilidad política de acercar sus metas si no es -insisten - asumiendo la capacidad propia de implementar sus derechos y no subiéndose al carro de una constituyente que, si bien impulsó el levantamiento popular, lo terminó cooptando la clase dirigente impugnada, por lo que no habría garantías. La oferta de escaños reservados no la consideran por no responder a las garantías que le corresponden al Pueblo Mapuche de acuerdo al derecho indígena internacional. Como vemos, no ha sido fácil implementar esta aspiración que, por lo visto, adolece de una estrategia que rompa, por una parte, con cierta anomia mapuche que parece atrapada en políticas clientelares y/o que ve en el Estado su fin individual como colectivo. Desde otro posicionamiento, las posibilidades de participación política abiertas por el escenario constituyente han generado expectativas en otros segmentos del movimiento mapuche, en particular respecto a la posibilidad de obtener escaños reservados. Quienes ven esta posibilidad como una estrategia política, no lo hacen desde una misma plataforma y lo que los puede diferenciar es la mayor o menor vinculación a la partidocracia chilena. Los militantes mapuche de partidos han hecho un objetivo político de esta posibilidad y han, junto a quienes - no teniendo ni queriendo una vinculación de ese tipo- han cerrado filas respecto a la cantidad de estos escaños proporcional al porcentaje de poblacional que representan según el último Censo (24 supernumerario a los 155 en una Convención Constitucional). También comparten acuerdos sobre quienes votan (sin empadronamiento sino por auto identificación en papeleta exclusiva) y respecto a quiénes y cómo se eligen (candidatos promovidos por cierta cantidad de asociaciones o

290 Las prácticas de los estereotipos no son nuevas en política interétnica (Stuchlik, 1974), pero cuando un pueblo como el mapuche entra a la contingencia - como una tercera columna-, desordena la polaridad política nacional del pos binominalismo. Estos estereotipos reproductores de imágenes los podemos percibir desde los 90 en adelante. Entonces, se escuchaba "estos [los mapuche] quieren todo" y otros más adhoc al conflicto con las forestales, como el de "quema bosques", como si las plantaciones lo fueran. 
comunidades de acuerdo a zonificación). La diferencia del grupo partidista con quienes también se hacen expectativas de los escaños está en que estos últimos ponen como condición para los candidatos la no militancia partidaria ${ }^{291}$. Hasta ahora, la discusión y propuesta está en presionar a los parlamentarios para que adopten las modalidades y las reglas, pero todo hace ver que, como otros tópicos mapuche de carácter político, esto esperará y será parte de una negociación entre políticos chilenos. He ahí una de las observaciones que se le crítica por parte de quienes ven en este proceso una prolongación de lo que se llamó "la cocina", por cuanto se presta para validar un proceso que no centra la temática en lo indígena y en sus territorios, sino que hace de estos una representación minoritaria.

Una estrategia de mediana data cuyo objetivo es la liberación nacional mapuche ha continuado subyacente, en lo mediático, pero proliferando al costo de la militarización de los territorios. Sus objetivos o enemigos son el capital de grandes empresas y sus encadenamientos productivos que, en los últimos años, ha incluido a familias de las propias comunidades como suministradoras de servicios. Sus escenarios de despliegue son los territorios en los cuales la recuperación de tierras, o bien la resistencia al extractivismo de proyectos, los ha convertido en las zonas rojas del conflicto $^{292}$. Acciones de violencia política son reivindicadas por esta otra cara del movimiento mapuche, quien mantiene en las cárceles a algunos de sus luchadores condenados o en proceso, los cuales se baten en huelgas de hambres periódicamente, concentrando así la atención en las problemáticas. En el año 2019, sus acciones de sabotaje han estado presentes y, paradójicamente, si se esperó que estas aumentaran, sumándose a aquellas que trajo consigo el Estallido Social, pudimos constatar que no ocurrió. La respuesta del Estado ha sido aumentar la dotación de personal uniformado en las zonas, redoblando las acciones con carácter de terrorismo de Estado. Por lo mismo, la denuncia de militarización del conflicto ha estado en la palestra constantemente y es la cantera desde la cual distintos sectores, oficialistas, opositores, gremialistas y mapuche, construyen y circulan análisis y enunciaciones de lo que pasa, desnudando, ocultando y tergiversando, pero, sobre todo, jugándose la opinión pública a su favor en lo que se ha dado en llamar "una guerra sucia de baja intensidad".

Si bien los distintos y constantes focos de rebelión y agitación que trajo el 2019 tendieron a dispersar a la fuerza pública, estos ocuparon los meses estivales de vacaciones para dejarse caer sobre procesos de recuperación territorial que estaban siendo tramitados comunicacional y burocráticamente. La pandemia, con su inmovilización, dejó expuestas a aquellas comunidades

291 Los mapuches detrás de esta idea consideran que hay un horizonte libredeterminista ya expresado en la constituyente indígena de Bachelet 2 (Millaleo, 2017) y que por lo tanto los escaños son un paso complementario a los derechos políticos del Pueblo Mapuche, una de las estrategias que debe complementarse con las otras presentes en el movimiento político mapuche (Mapuexpress, 2020).

292 Trabajos que se centran en estos movimientos y sus argumentos encontramos en Pu lov, 2017. Otro que innova en la aplicación de la interdisciplinariedad en la reconstrucción histórica y territorial, fue el que suministró elementos de juicio en la causa de las comunidades de Kurakautin en contra de los proyectos de mini centrales de paso. Ver: Melin et AL., 2019. 
en disputa territorial que fueron reprimidas con costos de vida y desplazamientos masivos durante la primera mitad del $2020^{293}$.

\section{La contradicción etnoclase vs pueblos naciones. Alianzas interétnicas}

¿Procesos de etnogénesis? La aparición multitudinaria de la wenufoye en las movilizaciones a nivel país de ese 2019, así como la des-monumentalización de íconos inscritos en espacios de memoria oficiales ${ }^{294}$, parecen ser poderosas señales, en el terreno simbólico, de lo que serían motivaciones profundas de una sociedad chilena que cuestiona el carácter y rol del Estado hacia los pueblos originarios, generando identificación o producción de sentido con empatía, que había comenzado en un fase más intelectual y artística, con el Estallido terminaba desbordándose y entroncando con aquellas corrientes políticas y filosóficas que, con experiencias disímiles en Latinoamérica, han devenido en los estados plurinacionales de la zona andina (Ecuador, Bolivia) ${ }^{295}$.

El año 2019 fue la punta del iceberg de un tema más profundo que arrastra la sociedad y es su Estado. Si bien en la historia, como en la actualidad, subsisten corrientes de opinión favorables a la inclusión de lo indígena en el Estado, reconociendo sus legítimos derechos, finalmente la opción hegemónica ha sido la de aquellos sectores que se han propuesto construir y situar lo indígena desde una otredad, inferiorizada y tutelada. Si el pueblo de Chile fue el que se comunicó simbólicamente a través de la bandera y la desmonumentalización, echando a correr la idea de una plurinacionalización del Estado, entonces, quienes se restan de esta iniciativa - la oligarquía-, desde una opción política - cuya hegemonía disminuye y aparenta llegar a su fin, si no llegar a su fin, conformarían no solo un estrato social acomodado, exclusivo y con poder, los ricos, sino una etnoclase que con su ideología o etnicidad creó y definió la nación (uniforme, monocultural), inscribiéndola jurídicamente a contar de la Constitución de 1833.

Si es que el pueblo chileno tiene sus raíces en los pueblos de indios, en la esclavitud afro e indígena del siglo XVI en adelante, en las migraciones del siglo XIX y, hasta ahora, en la complejización de las transformaciones económicas laborales con sus construcciones identitarias (étnicas como de clase), políticas y religiosas, entonces, sus fricciones con los intereses de los pueblos indígenas no son de carácter estratégico, como sí —en algunos

293 Uno de estos casos fuese mencionado en la represión con muerte del werken de la comunidad wente winkul mapu, Alejandro Treuquil de Collipulli, quien había denunciado el hostigamiento de Carabineros a su comunidad y había recibido amenazas de muerte por parte de esta misma institución (Comunidad, 2020), pero también están los casos de la Fusta en Lonkimay y, en pleno Temuko, el de la comunidad Juan Currin, ambas allanadas, desalojadas y destruidas sus instalaciones.

294 Un escrito del momento que ocurre el fenómeno lo leemos de Huinca (2019). Habría que complementar que no son las únicas expresiones del trasfondo impugnador contra el relato histórico oficial. Los cambios de nombre de calles o plazas y de comunas (como Saavedra) ocurren de facto de hace décadas, pero no habían afectado tan masivamente alos monumentos.

295 En el año en cuestión hicieron su aparición textos que, como reacción al estancamiento que adquirían las relaciones interétnicas e interculturales en Chile, comparaban la forma de resolver conflictos entre los estados y los pueblos indígenas (Vargas, 2019), y anunciaban a su vez la crisis del modelo multicultural, cuya práctica recién estábamos experimentando en Chile en una fase más declarativa (Zapata, 2019) 


\section{Capitulo 10. Página 196}

casos- de índole geoeconómica en los territorios de asentamiento histórico mapuche ${ }^{296}$. No ha estado en sus entrañas el sojuzgamiento y marginación como opción u oposición fundamental ${ }^{297}$. El golpe del 73 fue una refundación del Estado y la sociedad, no solo en conexión con la Guerra Fría internacional, sino con la historia nacional, hegemonizada por la oligarquía en su expresión más reaccionaria y colonial (Barnaby, 2017). Así las cosas, la pugna o contradicción no es entre pueblos como sí entre estos con quienes fueron el motor de la historia durante el siglo XIX, legándonos un Estado excluyente, opresivo, capitalista, patriarcal y colonialista, es decir, el Estado-Nación.

De estar esta lectura en lo cierto, se requiere de la descolonización como un propósito estratégico compartido interseccionalmente (géneros, clases, étnias) por la sociedad en su conjunto y de la autodeterminación de los pueblos e individuos como un horizonte que puede hacer alcanzable las aspiraciones que, para el caso mapuche, se han formulado en los parámetros de la autonomía político-territorial.

\section{¿El momento constituyente como oportunidad histórica?}

Los mapuche, en su conformación histórica, no tuvieron un poder central que los formateara. Una de las tesis respecto a la nación chilena y su Estado, de acuerdo a Mario Góngora, entre otros, alude a que es la aparición del Estado en el periodo poscolonial, quien hace de instrumento no solo para centralizar los procesos políticos de toma de decisión, sino también para subordinar al nuevo esquema a todos los pueblos y sus territorios tras una idea única de proyecto país y de nación.

Los mapuche mantuvieron a raya ese modelo que se les quiso imponer, hasta que a contar de las década del sesenta del siglo XIX, y por medio de una guerra, se le hizo entrar subordinadamente a este orden. Ese esquema hoy está siendo cuestionado ya no solo por los pueblos indígenas del país, sino por los propios chilenos. Los vientos de plurinacionalidad que soplan desde el 18 de octubre, cada vez con más intensidad, están buscando zafarse de la camisa de fuerza que se le impuso desde el siglo XIX y que el golpe volvió a refundar, pese a los intentos habidos durante el siglo XX por transformar esa historia tras proyectos como lo fueron la revolución en libertad o la vía chilena al socialismo. Actualmente, se discute una propuesta de escaños reservados para la Convención Constituyente o Mixta, para promover en esta participación "proporcional", pero en minoría política, las ideas fuerzas que impulsa la lucha de los pueblos indígenas del país.

296 “Aprendí el VOCABULARIO del AMO, dueño y PATRón... me MATAROn TANTAS veces, por LEVANTARLES LA voz". En esta composición, "el hombre es un creador" y en ese pasaje en particular Víctor Jara une su experiencia y expectativas como generación (en pleno proceso de reforma agraria y de vía chilena al socialismo) con aquellas que les antecedieron, viviendo en precariedad y sin mayor expectativa que resistir. Nacido y criado en mundos rurales de Ñuble y Lonken, con toda seguridad su imaginario (como el de muchos más) lo poblaban los pobres, los labradores, inquilinos, gañanes, los antepasados indígenas atrapados por la conquista.

297 Los sucesos de la independencia de Chile impactaron duramente al mundo indígena, una de las etnoclases de la sociedad colonial. El proceso puso término a los pueblos de indios "liberando" sus tierras y sus cuerpos (tras la ideología liberal imperante) para que fueran tomados por la gran hacienda. Esa desestructuración se vio aumentada por los reclutamientos forzosos para las guerras interoligárquicas. Muchas familias que huían de esa realidad presionaban sobre la frontera del Bío Bío para acceder a tratos de mediería o arriendo con los mapuche. No habrían tenido intereses geopolíticos, como si contar con tierras que les permitieran escapar al modelo hacienda y sus guerras. Este proceso siguió durante la conquista chilena del WALLMAPU y la posguerra y hoy conforman un campesinado "amapuchado" si es que sobrevivieron de manera independiente o "chilenizado" si es que lo hicieron orbitando el latifundio nacional y/o colono. 


\section{Capitulo 10. Página 197}

Esto está en proceso y aún no podemos precisar si se consuma o no, pero es una poderosa y sospechosa señal el que haya quedado para el final, luego de acordar lo de la paridad de género y la participación de los independientes ${ }^{298}$. En la sociedad mapuche que me toca observar y en la que convivo, hay confusión y resistencia producto, en parte, a una desconfianza en estos intentos que, si bien los gatilló el Estallido y la movilización social, los han buscado definir la partidocracia y quienes tienen el poder, sobre todo económico. Considero y constato que se viene concibiendo y debiera tener lugar dentro de poco un proceso constituyente propio de los pueblos originarios (invocado por líderes del movimiento, pero sin asidero aún), es decir, donde lo que se resuelva no quede a voluntad del juego de mayorías/minorías de los chilenos y a su voluntad. En 2023 se conmemoran los 230 años del parlamento de las canoas, también los 220 años del último parlamento (de Negrete) sostenido con el mundo hispano. Estas efemérides no paran, pues ese mismo año será el bicentenario del parlamento de Yumbel y en 2025 el de Tapiwe. Respecto a este último, quedó apuntado en su artículo 29 que el Estado (chileno, republicano) velaría por el próximo encuentro de iguales características, cuestión que nunca llegó, como sí una guerra de veinticinco años. Quizás esos sean los espacios constituyentes que se invocan, pasando de minorías supra numerarias (a manera de apéndice de la Convención Constitucional) a sujetos políticos y de derecho en sus propios territorios. Las cartas están echadas, hay que ver qué jugadores se atreverán a jugarlas. Quiénes, con quiénes, y contra quiénes.

298 La derecha teme al incremento del número de constituyentes, pues se haría más incierto controlar el tercio que requiere para frenar las iniciativas contra sus intereses. Por lo mismo plantea escoger por medio un empadronamiento un equivalente de escaños proporcional a los inscritos en los registros de votación de la Conadi, o sea, la nada. A lo más indica un representante por pueblo, 9 o 11, pues hay reconocimientos de pueblos en curso. 


\section{Bibliografía}

COMUNIDAD DE HISTORIA MAPUCHE (2020). "La pandemia del Racismo: de George Floyd a Alejandro Treukil”. (Declaración) Disponible en: www. comunidadhistoriamapuche.cl DÍAZ-POLANCO, H. (2005). "Etnofagia y multiculturalismo”. Revista Memoria, número 200. HUINCA, H. (2019). "El derribo de estatuas en las plazas de Chile y Wallmapu. La desmonumentalización de los iconos de la memoria histórica colonial”. 15-11-2019 Disponible en www.comunidadhistoriamapuche.cl

MAPUEXPRESS (2019). "Fracasada Consulta Indígena Piñera-Moreno: otro ejemplo de mala fe". (Editorial) Disponible en: www.mapuexpress.org/2019/08/04

(2020) Comunicado: Orgnizaciones indígenas presentan indicaciones a proyecto de reforma constitucional de escaños reservados para Pueblos Originarios. En:

www.mapuexpress.org/2020/08/20

MATAMALA, D. “Anatomía de un paro”. (Columna) Diario La Tercera 29/08/2020 MARIMAN, P. (2018). "De sujetados a sujetos: el caso mapuche en el Ngulumapu”. En: Díaz Crovetto G., Binimelis Espinoza H.,Pantel B. (Editores). Abriendo el Diálogo (In) Disciplinar. Perspectivas, Reflexiones y Propuestas desde el Sur. Ediciones de la Universidad Católica de Temuco. Temuco, pp. 101-116.

MELÍN, M., MANSILLA, P., ROYO, M. (2019). CArtografía Cultural del Wallmapu. Elementos para Desconolizar el Mapa en Territorio Mapuche. LOM ediciones, Santiago de Chile.

MILLALEO, S. (2017). Los pueblos originarios ante el horizonte de una nueva constitución. En: Revista anales Séptima serie. № 13/2017

NAHUELPÁN, H. (2013). “Las 'Zonas Grises' de las Historias Mapuche. Colonialismo Internalizado, Marginalidad y Políticas de la Memoria”. Revista de Historia Social y de las Mentalidades. Volumen 17, № 1: 11-33. Universidad de Santiago de Chile.

PINTO, J. (2001). “La ocupación de la Araucanía a travé de historiadores, novelistas, poetas y dirigentes mapuche". Investigando y educando: Estudios para el análisis y la aplicación. Universidad Metropolitana de Ciencias de laEducación. Santiago: LOM Ediciones.

PU LOV Y COMUNIDADES LAVKENCHE EN RESISTENCIA (2017). ¡XipamünPu ülka! La usurupación forestal del Lavkenmapu y el proceso actual de recuperación. Historia de cómo Mininco y Bosques Arauco se hicieron dueños legales del Lavkenmapu y la Cordillera de Nahuelbuta. Libros del Perro Negro, Santiago de Chile.

QUIDEL, J. (2020) "Fey ga akuy ti ahtu. Entonces el día llegó una lectura de la pandemia desde un mapuche rakizuam". Disponible en: https://www.comunidadhistoriamapuche.cl

RAMAY, A., LONCON, E. y MIRANDA, P. (2017). Violeta Parra en el Wallmapu. Su encuentro con el canto Mapuche.Centro de Estudios Interculturales e Indígenas (CIIR) y Pehuén. Santiago de Chile. 
Capitulo 10. Página 199

STUCHLIK, M. (1974). Rasgos de la sociedad mapuche contemporánea. Ediciones Nueva Universidad. Santiago de Chile.

VARGAS, R. (2017). Pewmas /Sueños de Justicia. Lonkos y dirigentes mapuche versus en Chile en la Corte Interamericana. Lom ediciones, Santiago de Chile.

YAÑEZ, N. y AYLWIN, J. (2007). El Gobierno de Lagos, los pueblos indígenas y el "nuevo trato": las paradojas de la democracia chilena. Ediciones LOM, Santiago de Chile. 
